remembrance, such acts were disproportionately appreciated in relation to the act.

\section{G240(P) COMPETENT WARD CO-ORDINATORS-MEETING TRAINING NEEDS THROUGH SIMULATION}

C Scaife, V Kellett, M October. Nursing, Sheffield Children's NHS Foundation Trust, Sheffield, UK

\subsection{6/archdischild-2015-308599.233}

Aims Taking charge of a ward is daunting for newly qualified nurses.

This abstract describes the development of a ward co-ordinators competency pathway, written to support and develop band 5 paediatric nurses in a leadership role, following Trust workforce review re-defining the band 5 role, requiring them to coordinate on a shift basis, post-preceptorship.

The development of this pathway responded to the skill mix review comparing our nursing bands with other specialist children's Trusts. ${ }^{1}$

Methods Review of national paediatric job descriptions and band 5 role. Trust band 5 job description rewritten against AFC national profile and matching other paediatric Trust band 5's.

Consultation with other Trusts reviewing post-preceptorship training programmes for band 5 nurses.

Trust steering group consisting of educators and nurse managers to design a training programme enabling band 5 nurses to become competent practitioners.

Band 5 nurses consulted to determine their development needs for this challenging role.

Support gained from Trust Nursing Executive and Learning and Development Department.

Results This learning consists of a Trust designed bespoke training day utilising simulation to introduce band 5 nurses to both clinical and management scenarios, complementing an accompanying pathway/clinical competencies booklet to be completed with a "buddy" in their clinical workplace within a specific timeframe.

A local evaluation of the project shows that of 17 band 5 nurses who have completed the pathway, 9 are satisfied and 8 extremely satisfied with the efficacy of simulation day as a teaching method.

Conclusion The study day uses a blended learning approach utilising simulation, group work and role play and is facilitated by Clinical Nurse Educators, Matrons and Senior nurses.

Both the day and pathway document promote a reflective and interactive approach, highly valued by band 5 nurses going through the programme and has resulted in supported and competent ward co-ordinators.

We have developed a unique and cost effective pathway which can be adapted to meet varying clinical staff groups.

It encompasses modern technologies/teaching methods, resulting in essential staff development/retention and better patient safety. $^{2}$

\section{REFERENCES}

1 Civil Eyes Research. Civil Eyes Research Project with Specialist Children's Hospitals. www.civil-eyes.com, 2010

2 DoH 2011 - A Framework for Technology Enhanced Learning http://www.dh.gov. uk/publications

\section{G241(P) ECHOCARDIOGRAMS IN CHILDREN - A PARENTAL PERSPECTIVE}

${ }^{1} \mathrm{M}$ Ranaweera, ${ }^{2} \mathrm{P}$ Venugopalan. ${ }^{1}$ Paediatrics, Queen Elizabeth Hospital, London, UK; ${ }^{2}$ Paediatrics, Royal Alexandra Children's Hospital, Brighton, UK

\subsection{6/archdischild-2015-308599.234}

Introduction and aim Cardiac murmurs are reported in 50-90\% of children at some time in their life, but only $1 \%$ are pathological. It is widely questioned whether performing echocardiograms on these children with asymptomatic murmurs is cost-effective or not. We designed this study to survey parents of children who had echocardiograms for asymptomatic heart murmurs which then proved to be benign.

Methods All new referrals for 'asymptomatic heart murmurs' to the paediatric cardiac clinic, run by a paediatrician with cardiology expertise, over a one-year period were reviewed. The parents of children with normal echocardiograms were requested to answer a questionnaire that elicited their experience of the echocardiogram and its impact on their concerns. Permission for this study was obtained, and consent sought from contacted parents.

Results 166 new patients attended the clinic during the study period, 67/166 were for asymptomatic heart murmurs. 58/67 of these patients had normal echoes. Among the 58patients, 51 were contacted by telephone for the survey (Table 1). None of these children had any repeat consultations for the murmur, and parents were convinced that the echo gave them the reassurance that they badly needed.

Conclusions Our study concluded echocardiograms provide parents with a satisfactory conclusion to the consultation. This may be a cost-effective method in reducing repeat consultations for the same concerns.

Abstract G241(P) Table 1 Salient results from the survey $(n=51)$

\begin{tabular}{|l|l|l|l|l|}
\hline Survey question (shortened for abstract) & yes & No & undecided & $\begin{array}{l}\text { P value } \\
\text { square test) }\end{array}$ \\
\hline Was the scan useful? & $92 \%$ & - & $8 \%$ & $<.001$ \\
\hline Did the scan reassure you? & $100 \%$ & - & - & $\mathrm{n} / \mathrm{a}$ \\
\hline $\begin{array}{l}\text { Would the clinician's explanation without } \\
\text { echo be reassuring? }\end{array}$ & $14 \%$ & $84 \%$ & $2 \%$ & $<.001$ \\
\hline $\begin{array}{l}\text { Do babies with benign/innocent/normal } \\
\text { murmur need an echo? }\end{array}$ & $94 \%$ & - & $6 \%$ & $<.001$ \\
\hline
\end{tabular}

